\title{
A Tentative Study on Differences and Integration of Sino-Western Filial Piety Culture
}

\author{
Xinrui Yuan (Corresponding author) \\ School of Software, Dalian University of Foreign Languages \\ 6 South Lvshun Road, Dalian 116044, China \\ Tel: 86-411-8611-1150_E-mail: xinrui_yuan@yahoo.com.cn \\ Qing Wang \\ 19 West Yalvjiang Street, Yuhong District, Shenyang 110032, China \\ Tel: 86-24-8217-5643 E-mail:wq5891@sina.com
}

Received: February 18, $2011 \quad$ Accepted: March 30, 2011 doi:10.5539/ass.v7n8p97

\begin{abstract}
Filial piety has become an important cultural symbol of civilization in Chinese national vitality which is different with others'. For thousands of years, it has been regarded as a traditional virtue and permeated into the national blood and bone. The Chinese filial piety culture and thought are limited to the nature and influenced by the Confucian ideology. There is also filial idea in the Western culture, which is lean to surpass the nature, and is affected by the Christianity; however, due to various reasons they are in obviously different forms. In the wave of globalization, a large-scale importation of Western thoughts and culture has collided with traditional Chinese thoughts and culture, filial piety is no exception. The paper focuses on exploring the differences and integration of filial piety between Chinese and Western cultures, and the factors contributing to this dissimilarity would be identified. The paper indicates that there are huge differences of the Sino-Western filial morality culture due to their diverse social and historical backgrounds as well as the reasons lie behind geography, nature and values. Bearing these differences in mind can not only reduce unnecessary conflict and clash but enhance mutual understanding and respect in cross-cultural communication, hence seek to the possibility of narrowing the cultural gap. Meanwhile, the two filial ideas could find ways to form the complementarities and coexist harmoniously.
\end{abstract}

Keywords: Family, Filial piety, Cross-cultural communication

\section{Introduction}

Filial piety as an ethical concept has a long history and deep social foundation in China. It was developed by Confucian classics and related to past dynasties systems, and gradually transcended its initial ethical values which included respecting ancestor and honoring parents to complicated forms which related to kinship, political system, social organizations and other aspects of life custom. Therefore, it not only became the core of Confucianism which is the subject of Chinese traditional culture but also became the nuclear concept of primary culture spirit of Chinese culture. In the new period of reform and opening up, our communication with the West is more extensive. The western parent-child relationship is absorbed and accommodated largely. Nevertheless, there are still remarkable differences between two culture systems.

Due to various history reasons, the problem of filial piety was forbidden field before the 1980s in Chinese Mainland. The recent decades of academic research have acquired important achievements; however, modern Chinese filial piety culture has not been researched completely and systematically in one monograph by academia. Meanwhile, in the West, study on this topic is less let alone comparison of both.

This research paper employed a large sum of secondary documents to make a tentative study on the difference and integration of Sino-Western filial piety culture by tracing their origins and analyzing the reasons that lie behind from geography and nature, history, social, and values, etc.

By viewing the above mentioned facts, this research paper will make a relatively comprehensive study on the 
task of comparing the two filial piety cultures and do some contributions to fill the blank in this field. Therefore, the study has realistic and significant implications in cross-cultural communication.

The intention of composing this paper is not just simply listing some phenomena and analyzing the cultural explanation behind those phenomena but to promote a better understanding between Chinese and Western people by comparing the two filial piety cultures.

\section{Comparison of Sino-Western filial piety culture}

\subsection{Chinese filial piety culture}

The Chinese traditional virtues involve in all aspects of social life with extremely rich contents in the five thousand years of glorious civilization records. Filial piety as one of the traditional virtues has a long history in Chinese culture, not only is the concept of caring for parents in the family, but also an important social norm in political order in several thousand years. As the earliest ethical moral category which accessed to family values, there are complete theories of filial piety in Chinese nation.

\subsubsection{Origin and development of filial piety}

When and where did filial piety originate? It should be said that filial idea originated along with the birth of human beings, which is the innate nature and natural emotion of mankind; however, China is unique to upgrade filial idea to Tao.

"Chinese filial piety originated from the 11th century BC, and was clearly put forward from the Zhou Dynasty, which can be proved by the unearthed bronze inscription of Zhou Dynasty. For example, the Chinese character Xiao (filial piety) has appeared in large numbers on the Western Zhou bronzes. There were many discussions on filial piety in The Book of History and Book of Chang written in Yin and Zhou dynasties, and The Book of Songs, that is to say filial piety was a fairly common moral ethics at that time." (Shen, 2008, pp. 5)

Historically, the first period which emphasized filial piety was the Spring \& Autumn Period, the era of the Eastern Zhou Dynasty, from 770 BC to 476 BC. At that point, the ferocious Rong and Di tribes raided the empire from the west, and internally, the nobles carved pieces of the country into their own private fiefdoms. The Zhou emperor was a figurehead and the society was in chaos as the old order collapsed. At the same time, amongst themselves the nobles fought terrible, endless wars over the remnants of Zhou power. It was in the fiefdom of $\mathrm{Lu}$, in the late Spring \& Autumn, the Confucius lived. Confucianism which is created by Confucius played an important role in the process of redeveloping the patriarchal ethics which was centered by filial piety. Therefore, the Confucian filial piety ethic became the core ideology in the coming thousands of years of China's feudal society.

The unified feudal empire of China was relatively stable in Qin and Han dynasties. After a period of exploration and reflection in the early Han dynasty, the ruling class came to realize that only Confucianism was most suitable for the patriarchal family system. Therefore, the Confucian concept of filial piety received so unprecedented attention that ruling the world with filial piety occupied the mainstream of ruling thought. It is recorded that there are as many as 32 recordation of nationwide commendation and conferment of the 'title of nobility' on filial piety in Book of Han and The History of the Late Han Dynasty. According to Shen there was also a special post called "XiaoLian" (filial piety and incorruptness) in the country. In addition, the Han emperors added the character "Xiao" before their posthumous titles (Shen, 2008, pp. 12).

\subsubsection{The connotation of filial piety}

As to the literal sense of Xiao, it is:

"The upper part, Lao, represents the old parents, and the lower part, $Z i$, represents the child; Lao is above, and $\mathrm{Zi}$ is below, which means that it is filial piety that children are obedient to their parents. Meanwhile, from the point of view of action, the child carries the parents on the back, which means when the parents are senile and doddering they need the children to help them." (Shen, 2008, pp. 2)

Filial piety plays a fundamental and key role in traditional ethical life of China ruled by Confucianism, so there are a lot of teachings and guidance about it in many classics in which filial piety is praised as the highest category of theories. For example, the Master - Confucius said that filial piety and fraternal respect can surely be regarded as the fundamentals of Goodness (Zhou \& Mei, 1992, pp. 3). After the Spring \& Autumn Period, individual family was relatively independent, thus to support the parents became the main elements of filial piety gradually. Confucius made detailed description on how to maintain the parents. For example, Confucius said that as a son or a younger brother, he should be filial to his parents at home and respect his elders abroad (Zhou \& 
Mei, 1992, pp. 5). Besides, he taught people that while parents are alive, the son does not go abroad to a far distance. If he does go abroad, only goes where he said he was going (Zhou \& Mei, 1992, pp. 65). In addition to the obligation of supporting one's parents, he pointed out that filial piety also composed of caring love and sincere concern. For example, when Zi You asked about the meaning of filial piety, the Master answered him that filial sons nowadays are people who see to it that their parents get enough to eat. But even dogs and horses are cared for to that extent. If there is no feeling of respect, wherein lays the difference? (Zhou \& Mei, 1992, pp. 20). In other words, filial sons maintain their parents are out of the heartfelt gratitude for the love and care they received from childhood because the biggest difference between human beings and animals is that people have thoughts and feelings, hence they should treat parents kindly and pleasantly.

The above expositions talk about primary emotions based on the natural kinship. Chen thinks that filial piety also means to identify and inherit the spirit and ambitions of one's parents and to carry forward it from generation to generation (Chen, 2005). Just as the Master said that when a man's father is alive, watch his aspirations; after his father's death, observe his conduct. If for the whole three years of mourning he maintains unchanged his father's way of running things, then he can really be called a faithful son (Chen, 2005, pp. 9). In addition to love and respect one's living parents. Wu (2010) believes that it also implies the meaning of respecting and loving those parents and ancestors who have already died. In The Analects OF Confucius there are also similar teachings, for example, Master Zeng once said that when funeral rites of the parents are carefully performed and due respect shown for the Good of the ancestors, the moral quality of the people will naturally grow in purity and honesty (Zhou \& Mei, 1992, pp. 8).

The above expositions covered various aspects of family life, which laid the foundation for filial piety to penetrate into every corner of society.

Chinese filial piety culture has important political connotations. In feudal society when families and the country had the same structure, the filial duty was regarded as loyalty. One who is filial to his parents must be loyal to the monarch, because the emperor is like the father of the country. Ruling the world with filial piety became the experience of successful governance, therefore filial culture is not simply limited to support and respect parents, but enlarged and extended obviously.

\subsection{Western filial piety culture}

There are three sources of Western culture: the ancient Greek civilization represented by Socrates, Plato and Aristotle; the ancient Hebrew Judaism civilization, and the ancient Roman civilization. In the West, there is no corresponding concept of filial piety with that of ancient Chinese, but this is not to say that there is no filial idea in Western history. In the early Greek and Roman, it is also very particular about supporting and respecting one's parents. For example, Plato once said:

"Next comes the honor of living parents, to whom, as is meet, we have to pay the first and greatest and oldest of all debts, considering that all which a man has belongs to those who gave him birth and brought him up, and that he must do all that he can to minister to them, first, in his property, secondly, in his person, and thirdly, in his soul, in return for the endless care and travail which they bestowed upon him of old, in the days of his infancy, and which he is now to pay back to them when they are old and in the extremity of their need. And all his life long he ought never to utter, or to have uttered, an unbecoming word to them; for of light and fleeting words the penalty is most severe." (Plato, 1988, pp. 526)

The meaning of this passage is extremely closed to the connotation of Chinese filial piety. The three sources blended then and constituted the Western culture system in the form of Christianity. Therefore, to explore the western filial piety culture must study "the Bible" which has been considered as a source of western literature and artistic creation. Many moral norms of Western societies are also rooted in it. It is recorded that God promulgated ten commandments to human society, and the fifth one is that honor your father and your mother, that your days may be long upon the land which the Lord your God is giving you (Wang, 2009, pp. 14). There are also similar teachings and commandments in Deuteronomy and Proverbs, etc. For example, "Honor your father and mother, as the Lord your God has commanded you that your days maybe long, and that it may be well with you in the land which the Lord your God is giving you" (Wang, 2009, pp. 22). "Listen to your father who gave you life, and don't despise your mother when she is old" (The Holy Bible, pp. 594).

However, in the comparative study of Chinese and Western culture, the author discovered that apart from The Bible, the West has little literature that systematically described filial piety, which is the opposite situation in China. 


\subsection{Comparison of Sino-Western filial piety culture}

When we explore this issue, the first problem is in the West whether there is filial piety similar to China or not. From the Bible mentioned before we know that there is concept of filial piety, but it did not form a complete system like China. It is the unique quality of China which is not possessed or even shared by any other culture in the same way. Just as the American writer Arthur Henderson Smith said in his book Chinese Characteristics:

"To discuss the characteristics of the Chinese without mentioning filial piety is out of the question. But the filial piety of the Chinese is not an easy subject to treat. These words, like many others which we are obliged to employ, having among the Chinese a sense very different from that which we are accustomed to attach to them, and a sense of which no English expression is an exact translation." (Smith, 1991, pp. 151)

Before we discuss the differences between the two, we must admit that filial piety between China and the West still has similarities because human beings as a whole, human culture is not isolated.

The western Mothers' Day is a case in point and the children will look in their parents on Christmas and their parents' birthday. Western literary works are also on the contents of filial piety. For example, in the famous tragedy King Lear, Shakespeare condemned the duplicity of King Lear's eldest and the second daughter, but praised the third daughter's filial piety to her father. In addition, Dickens' A Tale of Two Cities also described the daughter's filial piety and love to her insane father.

From this point we can see filial idea in the West is still an indispensable part of moral principles. It is just not so well developed that reach the acme like in China. Nevertheless, compared with the differences the same points are still insignificant.

To begin with, the core of traditional Chinese filial piety does not appear in the Western culture. Chinese filial piety culture has infiltrated and flowed in all aspects of social life. Many places are famous for filial piety and dutiful son will be respected by the whole society. For instance, according to historical records, Dong Yong, one of the famous "twenty-four examples of filial piety", sold himself to a rich family to be a servant in order to bury his dead father, which was very touching and became a much-told tale (Shen, 2008, pp.6); whereas Western culture of filial piety is far not so well developed. Not only there is no place famous for "filial piety", but also no place is proud of it, not to mention such well-known figures as the "twenty-four examples of filial piety". To our surprise, according to statistics there is no one such entry included in the Application of English-Chinese Dictionary of English Proverbs (Hu \& Chen, 2007, pp. 48).

In addition, Chinese filial duty emphasizes no contradiction, which seems to be not the same in the West. They pay attention to equality between parents and child, not requiring the absolute obedience to the parents' will, and encouraging children to have independent opinion. In fact this is a reflection of freedom, independence and individuality. As to supporting parents, Xiao said that from the angle of ethical practice and obligation, it is also the obligation of children, but not that absolute as China (2001).

Recently in the West, Jeffrey Blustein made the most detailed and authoritative exposition on filial piety. We can briefly express his view: grown children owe their parents a lot, but the parents have no right to claim the same favor as a debt on their children $(\mathrm{Li}, 2005)$. Such theory based on his concept of obligation which is distinguished into two kinds: one is duties of gratitude and the other is duties of indebtedness. Only the one who has duties of indebtedness must be responsible for the claim of the dunner while the one who has duties of gratitude is different. And children to their parents are just duties of gratitude. What is stressed in parentage is friendship and love. Quite the opposite, in the Confucian culture filial duty is a self-evident moral obligation. Zhao in his paper gives us a convincing example that few Chinese will ask the question that why we should fulfill our filial duties, even though somebody asked, "parents raised us" is the ultimate and irrefutable answer (2008, pp. 36).

According to the report of a sociologist, when asked the American senior citizens who should bear the obligation to financially support the elder, " $76.7 \%$ of the female and $80.3 \%$ of the male think it should be the responsibility of the government rather than the offspring" (Hong, 2007, pp. 75). In the West as early as 13th century or even earlier, aged support agencies have come into being. In other words, social endowment replaced family support. Therefore, the bound of family and parents to the child is relatively loose, naturally, there is no such requirement that while parents are alive, the son does not go abroad to a far distance. At the same time, children are still backbones in the network of economically supporting the old people at present in China.

In the next place, filial piety combined with ritual. From the daily life to funeral and sacrifice all have extremely complete and detailed requirements while western filial culture did not produce such complicated ritual demands, 
and much more simple and free.

The third one is based on the transcendence of its initial ethical values. Chinese filial piety is beyond the scope of a simple parent-child ethics, but integrated with politics, not only affects the socio-political structure, but also penetrates into legislation, education and other social aspects. In contrast, western filial piety is still the equal love and respect ethical feelings between parents and children.

The last difference comes from human-based filial piety and God-based filial piety. Wu argues that:

"In China, all the principles are products of human culture, or cultural creation. The human creative process started with the beginning of Chinese culture, together with the birth and growth of human feeling toward one's parents. The feeling is, in reality, the feeling of filial piety while in traditional West, moral principles, in general, are created by God or Spiritual Authority.” (Wu, 2010)

The reason that why one should fulfill filial duty is out of the fear of God and God's dorea, this is to say, honor one's parents should give way to honor God. The highest significance of filial piety is to God, the Father, rather than one's parents. Especially, when there is conflict between God and parents one should choose to stand on the side of God without the slightest hesitation. Just as in the Luke of the Bible, God said: "If any man comes to me, and doesn't hate his own father, mother, wife, children, brothers, and sisters, yes, and his own life also, he can't be my disciple" (The Holy Bible 973).

All in all, a brief review of the differences between Chinese and Western filial piety cultures are one is voluntary-based, people-oriented, and extended to other categories while the other one is right-oriented, God-centered and not beyond the scope of parent-child ethics.

\section{Cause analysis of the differences of Sino-Western filial piety culture}

The generation of any culture has its own social and historical backgrounds. Many factors contributed to the dissimilarities of Sino-Western filial piety culture could be identified, such as different natural, economic and political conditions.

\subsection{Clan standard vs. individual standard}

The living environment of each nation exerts significant influence on the emergence and development of its culture because human society can not develop isolated from the natural environment.

China's natural geographic environment is closed. Chinese nation grew up in the Yellow and Yangtze River valley where the Pacific Ocean located in the east, and high mountains and Gobi northwest; meanwhile the southwest is Hengduan Mountains and the Tibetan Plateau - the "roof of the world". Indian Ocean is in the south while the north is desert and jungle, which is far from or even isolated from other civilization centers. Although China has a long coastline, the marine situation is completely different from that of the West, such as Greece. It is not as peaceful and tranquil as the Mediterranean but boundless and choppy. People can only obtain very limited resources in some areas such as fishery or sea salt industry, let alone open up ocean routes. As a result, the ocean in Greece is a channel leading to the outside world, while in China is a natural barrier.

With vast plains, fertile land and rivers, and dense population, the region is very suitable for agriculture and animal husbandry, as well as the management of a self-sufficient economic life, but not for the development of an open commodity economy. Agriculture-based culture is fertile ground for collectivism. In traditional society, individual peasant economy has vulnerability in itself, so the farmers must be in a unit of family or clan, and work collaboratively to resist intrusion of natural disasters. Therefore, the Chinese emphasize the values of family and maintain close family links. Just as the Chinese proverb goes to forget one's ancestors is to be a brook without a source, a tree without a root (Zhang, 2004, pp. 215). The Chinese say that if you know the family, you do not need to know the individual (Samovar, 2008, pp. 105). People emphasize on the views, needs and goals of the group rather than oneself and cooperate with in-group members rather than distinguish from one another. Just as Li Yunchuan concluded that the community always stands before the individual (Li, 2008). As a result, a "we" consciousness prevails: identity is based on the social system and individuals trust group decisions; the individual is emotionally dependent on organizations and institutions (Samovar, 2008).

On the other hand, Western culture originated in the Aegean region where is mountainous and dry in summer, and not suitable for agriculture. Thus, people have long committed to the development of handicraft industry and commerce, gathered in some cities and always moved and migrated to other places. In order to do business, they traveled extensively, while home is just a hotel on the journey of life, hence western family is much looser than the Chinese family and has not much binding effect on the individual. Shi said:

"Americans view the family as a group whose primary purpose is to advance the happiness of 
individual members. The result is that the needs of each individual take priority in the life of the family. In contrast to that of many other cultures, the primary responsibility of the American family member is not to advance the family as a group, either socially or economically, nor to bring honor to the family name." (Shi, 1997, pp. 63)

Because "ever since the first settlers found a free land to escape the control posed by the king and churches, by priests and aristocrats, the American fostered a preference for individualism that places liberty and freedom on the highest position of life" (Jiang, 1987, pp. 56). Whereas, this is not to say that family is unimportant or even means nothing to an American. Actually, in their opinion a man without a happy family can't be portrayed as a successful man (Guo et al. 2007, pp. 73). Family is like a harbor, in which human spirits can find refuge from the highly competitive outside world and can be refreshed and restored for future struggle. Even the American President George W. Bush has a picture of his family on his desk in the White House. Guo et al. give us a vivid description in his paper which can help us to better understand what people's relationship within a western family:

"They are like different ships resting in the harbor, caring for each other and sharing with each other. But once a ship decides not to stay in the harbor anymore, it is free to go. That may explain why American families enjoy more democracy and individual freedom." (2007, pp. 73)

The example manifested that although family is very important in American culture, the minimum elements are still individual family members.

\subsection{Hierarchy vs. equality}

The stereotyped view of the Chinese family was a large extended family, with several generations and immediate families all living under one roof, thus "three-generation families are common, four-generation families are blessed and five-generation families are truly remarkable"(Guo et al., 2007, pp. 71). Consequently, such complex relationships among people in a big family need to be adjusted by the patriarchal and hierarchical system according to Confucianism. The superior naturally gains some privileges and advantages to the inferior. Everyone has a social rank and all are expected to know where they fit into the hierarchy and to behave accordingly, which was emphatically symbolized in the concept of filial subordination. This is very important in maintaining stability and unity of Chinese society which is based on a decentralized small-peasant economy. It can be said that filial piety is the production of patriarchal clan standard and the core of family ethics (Xiao, 2001).

In the West, such as in America, closely related to individualism is the value of equality which penetrates in every aspect of social relationship. Those settlers realized that they did not have any chance of getting any privileges as hereditary from the first day of arriving at the new continent. As we all know the famous sentence in the "Declaration of Independence" that we hold these truths to be self-evident, that all man are created equal; that they are endowed by their Creator with certain unalienable rights (Wild \& Blumer, 2000). Hence it is common that when two people communicate with each other, no matter how different their positions are, they intend to establish an equal atmosphere. Likewise, within a family, it tends to advance equality rather than hierarchy. Taking Growing Pains - a famous American large sitcom - as an example, in almost every episode, there are plots in which parents and children discuss or chat with each other equally. Even in some episodes, children quarrel with their parents, behaving like adults. It happens not only in the sitcom but also in daily life. In China, it is impolite and even forbidden. Parents should have the authority till the child grows up. For instance, opposite to Growing Pains, in I Love My Family, the first Chinese sitcom which is considered as the Chinese version of Growing Pains, once there is a talk between Jia Yuanyuan - the only child in the family, and other adults, most of the time it is the child who is criticized and ordered. It goes without saying that the parents own privilege to their child and it is reflected in the sitcom.

\subsection{Intergenerational integration vs. intergenerational differentiation}

Chinese filial piety tends to maintain family continuity, development, unity and stability, so it must emphasize intergenerational integration while Western culture which views people's freedom and equality as the highest value is bound to emphasize intergenerational fracture. The so-called intergenerational integration is to emphasize the recognition, consistency, continuity and unity of older generation and the next generation, parental generation and filial generation, and this is the fundamental spirit of Chinese filial piety. There is a strong bond between parents, children and other family members. On the contrary, most American family is a nuclear family, consisting of a husband, wife and their children. "Elder parents rarely live in the same home with their married sons and daughters and other close relatives" (Ingoldsby, 2005, pp. 99-13). Cultures that foster individualism offer less support to the child, he or she must quickly learn to be self-reliant. The support network 
in the United States, for example, is small. In the United States one might say that his achievement is mainly because of his ability and initiative (Zhang, 2004). According to the observation of Fei Xiaotong, the American parents' love to the child is also conditional; he said that American children understand from an early age that parents will not love you just because you are their child. Parental love is a prize not the child's right (1985, pp. 171). In the family, there is also a sharp distinction between the child's world and the adult's world. Liu Fengxia said that it is not uncommon for parents to put a newborn in a separate room that belongs only to the child to get used to having his or her own room, which is seen as a first step toward personal independence (Liu, 2005, pp. 52). When people getting old they will be sent to nursing homes rather than integrate into the homes of the children or grandchildren. It is generally known that in English "uncle" has a much broader meaning than in Chinese. Chinese people have such a fine division of the title while the westerners' is so vague is another proof that their family bond is not as close as Chinese. On the other hand, there are many old people who choose to live in retirement communities where they have the companionship of other old people rather than become too emotionally dependent on their children. Such intergenerational differentiation is just the premise and root of parent-child independence and equality as well as the basis of developing individualism.

\subsection{The old paramount vs. the young paramount}

Almost every culture shows some degree of respect for its elders; however, "the respect North Americans have for their elderly is indeed pale compared with the high value placed upon the elderly in other cultures, such as China" (Dodd, 1991, pp. 86).

Wang Lili argues that aging brings two related issues: senile spirit and rich experience (2004, pp. 21). Different social and cultural patterns have the different evaluations. For example, the US society pays more attention to the aspect of senility while the Chinese are more valued the aspect of experience. This is because China is a traditional nation characterized by agricultural society. In the long period of farming, the old people accumulated a sum of valuable asset, such as the grasp of the farming season, the use of work tools and the precaution of risks and emergencies during the farming, which is available for the young to learn. Therefore, Chinese value the aged as a source of experience and wisdom. "Older people have an advantage, and generally receive more attention than younger people. Such an attitude will be viewed by Chinese both as a gesture of respect and as a sign of sincerity" (Li, 2008, pp. 156).

In addition, in China, "old" is an honorific title, not flattery. Old workers, old sirs, old professors are all "respected elders". These titles are sweet and welcome. However, the word "old" in English is not necessarily a synonym for "good", but generally has more negative connotations than good because growing old is not exactly pleasant for people in youth-oriented American culture. Most Americans like to look young, act young and feel young, or at least young at heart. "Old people joke about how many years young they are, rather than how many years old" (English OnLine, 2010).“To a westerner, youth represents health, vigor, life and beauty” (Zhao, 2008, pp. 112). In consequence, people do not have much respect for their senior citizens. Nevertheless, such situation is inseparable from the western social background. With the rapid progress and development of the process of industrialization, the elderly are increasingly becoming the burden of social economic, scientific and technological progress. Intensive mode of production requires people to learn and use advanced technology continually; however, the physical and mental conditions or other aspects of old people are decreasing with age so that both the learning and mastery of new techniques will fall off remarkably, which means to result in the inefficiency of the update of new technology and social labor.

Such difference also can be seen from the two sitcoms we mentioned before. There are five family members in Growing Pains - three children and their parents, among which $60 \%$ of the characters are children and $40 \%$ adults. It is not difficult to imagine that there are more happenings acted by children and more humor created by them than by adults. By contrast, in I Love My Family, there is only one non-adult character among the seven main characters in the family. Obviously, it is an adult-centered family, not only because most of the family members are adults, but also most of the plots are acted by adults and developed among them. The child always played a minor role. According to figures, in the first 40 episode, in Episode 6, 7, 12, 14, 16, 17, 24, 27 and 31, which was nearly one quarter of the sitcom, the only child Jia Yuanyuan did not appear at all. On the contrary, the grandfather, the oldest people in this sitcom, took part in almost every episode and played a more important role than his offspring.

All these show that the old paramount and the young paramount are indeed an important reason which results in the difference of Sino-Western intergenerational values. Respecting the old will inevitably stress filial piety. Some people even think that filial piety is generated from the respect for the old. Whereas the Western culture is youth-oriented, this at least will not lead to a privileged position of the elder, but take an equal attitude towards the junior. 


\section{Integration of Sino-Western filial piety culture}

\subsection{Dialectical analysis of traditional Chinese filial piety culture}

Admittedly, filial ethics has the positive side; however, just as every coin has two sides, Yang believes that its negative sides are also can not be ignored (2007).

Firstly, the filial piety culture nurtured the authoritarian personality of the people, i.e. the slavish personality that is absolute obedience and self elimination. This made the whole nation develop a submissive personality of tame, dependence, lack of courage and creativity as well as lack of life and vitality. Individual achievements are not out of personal creativity and struggle, but of the obedience of social authority and social norms, and at home is a dutiful son, out a conformist.

Secondly, the filial piety culture led the conventional and conservative personality of the countrymen. Liang argued that the Chinese characteristic is esteem the past over the present, lack of adventuresome spirit and is reluctant to leave the place where one has lived long (Yang, 2007). This well manifested the Chinese characteristic of fear of change and lack of innovation

Thirdly, the filial piety culture resulted in the people's indifference of sense of right. Western ethics believes that all are equal and human rights are endowed by heaven, whereas filial piety as the start and rationale of patriarchy and hierarchy result in the ignorance of independent personality of the descendents. "Democracy, as an important sign of modern society, is a system in the public domain which grows out of the values of personal freedom, equality and right[...]"(Yang, 2007, pp. 636). However, such patriarchal filial piety causes difficulties for cultivating free and democratic spirit within Chinese society.

\subsection{Brief discussion on establishment of modern parent-adolescent relationship}

The differences of Sino-Western filial piety are indeed existed. Then, with the gradual integration of global politics, economy, and culture, we should think about how to conduct cross-cultural communication and how to deal with the contemporary parent-child relationship. The formation of any culture has its own historical conditions, rationality as well as the imperfectness. Seeking common ground while reserving differences, mutual promotion and co-development should be the basic principles of the contemporary cross-cultural communication.

Chinese filial morality culture is multiple and complex. It formed the Chinese nation's traditional virtues of respecting the old, meanwhile maintains the harmony and stability of family and society. However, on the other hand, the conservatism and inequality of parent-child relationship hinders the social progress to some extent.

The western families tend to place more emphasis on the needs, desires and individual freedom of the child, which in favor of promoting the social progress and liberating human personality. But there is also negative side. It is said that retirement-typically at age 65-brings a sharp decrease in personal income. Social Security benefits usually cannot make up the difference. Older people may suffer from poor nutrition, medical care and housing (English OnLine 2010). Nan Huaijin believes that this is the biggest loophole in the Western cultural system and social habits (1996, pp. 47). However, this is just the standpoint of a Chinese scholar; maybe western people do not think so. But it is self-evident that a full-fledged social security system should indeed settle the elderly down.

In fact, most Americans are worried that there is too much democracy in the home. The last twenty years have seen a significant decline in parental authority and children's respect for their parents (Shi, 1997, pp. 68). The American Arthur Henderson Smith said in his book Chinese Characteristics that Christian Western countries tend to dilute the family relationship, therefore, China's filial piety should arouse their attention (Smith, 1991). Meanwhile, in the course of cultural intercommunication on parent-child relationship between east and west, Hong Caihua hold that we should not only carry forward such good traditions as respect the old and cherish the young, but also adopt such reasonable factors as fairness between parent and child in western countries (Hong, 2007), so we can build up a modern new parent-adolescent relationship and a harmonious society in which the old or young, male or female enjoy themselves together as well.

\section{Conclusion}

By comparing and analyzing Chinese and Western filial piety cultures, the research paper draws a conclusion that Chinese and Western filial piety cultures differ remarkably. For these differences, we should not simply label it as good or bad but explore it in depth. The origin of Chinese filial piety can be traced back to as early as 11 th century BC and Confucianism is considered as its theoretical basis. Through the development of thousands of years, Chinese filial piety culture has been greatly enlarged to a wide range of almost every aspect of life 
custom. The Chinese culture and thought are limited to the nature and think about much of the relatives and the love to the parents, rather than individual's right or need, but this filial idea is limited to the consanguinity. In contrast, Western filial piety has not yet well developed with the passage of time; consequently, the content is limited. The Western culture leans to surpass the nature, and is affected by the Christianity, so its idea of filial piety is not limited to the consanguinity but God-based. The differences result from various reasons both subjectively and objectively, such as clan standard and individual standard, hierarchy and equality, intergenerational integration and intergenerational differentiation, as well as the old paramount and the young paramount.

Since modern times, feudal hierarchy and oppression of traditional filial piety have been eliminated and endowed with new connotations such as freedom, equality, and democracy, and begin to restore to its original state gradually. With the breadth and depth of globalization, this trend of mutual influence will continue to develop. There is a possibility that Confucian tradition and the Western tradition of democracy and freedom combine together to achieve co-existence to satisfy both sides. Indeed whether this thought can come true needs further study. For example, to what extent can one person accept two value systems at the same time? Along with this thought, we might have more to explore and harvest. In summary, if we want to live peacefully and harmoniously under the same roof, the best thing we must do is to make an understanding between Chinese and Westerners.

\section{References}

Chen, Zhiguo. (2005). Comparison of the ethic concept filial piety from confucianism and christianism. Hebei Academic Journal, (06), 52-58. (in Chinese)

Dodd, Carley H. (1991). Dynamics of Intercultural Communication, 3rd Edition. Dubuque: WBC Book Manufacturers.

Elder People in America. English OnLine. [Online] Available: http://eonline.dlufl.edu.cn/culture/westernculture/USCulture/Tzyc6elderpeopleinamerica.asp? (April 1, 2010)

Fei, Xiaotong. (1985). America and the Americans. Shanghai: San Lien Book Store Publishing House. (in Chinese)

Guo, Ping, Heng Luo \& Yan Zhou. (2007). Study of US-China cultures: comparison of family structure between china and the US. US-China Foreign Language, $48^{\text {th }}$ ser.5.9 (2007):71.

Hong, Caihua. (2007). "Feedback" and "relay": on parent-child relationship. Studies in Ethics (2):71-77. (in Chinese)

$\mathrm{Hu}$, Yuanjiang \& Chen, Haitao. (2007). On views of filial piety in chinese and western culture. Journal of Nanjing Forestry University (Humanities and Social Sciences Edition), (01):46-49. (in Chinese)

Ingoldsby, Bron B. (2005). Families in Global and Multicultural Perspective. Sage Publications, Inc.

Jiang, Ningkang. (2004). American Society and Culture. Nanjing: South University Press.

Li, Chenyang. (2005). The Tao Encounters the West: Explorations in Comparative Philosophy. Beijing: China Renmin University Press. (in Chinese)

Li, Yunchuan. (2008). A Panorama of Chinese culture. Dalian: Dalian University of Technology Press.

Liang, Suming. (1987). The Essence of Chinese Culture. Shanghai: Xuelin Press. (in Chinese)

Liu, Fengxia. (2005). Intercultural Communication Theory and Practice. Beijing: Peking University Press.

Nan, Huaijin. (1996). Generation Old, Something New Preface. Shanghai: Fudan University Press

Plato. (1988). The Laws of Plato. Thomas L. Pangle. Trans. Chicago: University of Chicago Press.

Samovar, L. A. (2008). Communication Between Cultures Third Edition. Beijing: Foreign Language Teaching and Research Press.

Shen, Hong. (2008). Xiao Xing Tian Xia. Beijing: Chinese Workers Press. (in Chinese)

Shi, Xinyuan. ed. and trans. (1997). Varieties in the Society of the United States. Shanghai: Dofang Publishing Center.

Smith, Arthur Henderson. (1991). Chinese Characteristics. Jilin: Yan Bian University Press.

The Holy Bible. Printcorp. LP, 2004.

Wang, Lili. (2004). The study of comparisons of the family-supported-age care system of orient and occident. 
Northwest Population Journal, (6):20-23. (in Chinese)

Wang, Wenming. (2009). HOLY BIBLE Famous Quotations \& Allusions. Wuhan: Hubei Education Press.

Wild, J.W. and N. Blumer. (2000). American Culture: A Course Book. Beijing: World Affairs Press.

$\mathrm{Wu}$, Joseph $\mathrm{S}$. Filial piety and Chinese culture. [Online] Available: http://thomehfang.com/suncrates5/xiaodao.html (May, 2010)

Xiao, Qunzhong. (2001). Filial piety and friendly affection: the differences of the intimate relationship of parents - sons between Chinese society and west world. Morals and Civilization, (1):40-44. (in Chinese)

Yang, Aihua. (2007). The limitation of filial piety ethics. Legal System and Society, (7). (in Chinese)

Zhang, Congyi. (2004). A Comparative Study of Western and Chinese Cultures. Changsha: Hunan People's Publishing House.

Zhao, Qizheng. trans. Geoffrey Bonnycastle. (2008). One World: Bridging the Communication Gap. Beijing: China Intercontinental Press.

Zhao, Zhongyue. (2007). Filial Piety: The different answers from the oriental and occidental culture. Xiangyin, (04). (in Chinese)

Zhou, Duwen \& Mei, Renyi. (1992). Analects of Confucius. Beijing: China Peace Publishing House. (in Chinese) 